\section{By the Numbers}

\section{Economic Data Revisions: What They Are and Where to Find Them}

\section{Katrina Stierholz}

\author{
"The past is never where you think you left it." \\ -Katherine Anne Porter
}

\section{Data Revisions}

Economic data is being revised often. On the first Friday of every month, the Bureau of Labor Statistics (BLS) publishes its Employment Situation Summary. This report describes the state of employment in the United States and two highly anticipated (and media-watched) employment numbers: The Unemployment Rate and Total Nonfarm Payroll Employment. The Unemployment Rate is based on a survey of persons who report they are seeking work but are not employed. The Payroll Employment Data are based on firms' reports of the number of people employed. Economists and others carefully watch the rise (or fall) of the total nonfarm payroll employment data. These data are a fundamental reflection of current economic conditions and a significant rise or fall will, in turn, influences economic decision-making by businesses and government.

There's a small rub, however, in the Payroll Employment Number: It is a very rough estimate and is revised the following month - and then again the month after-as more information arrives at the BLS. These revisions can be large and may materially change the picture of the economy. Here's an example: The first release (October 3, 2008) of the September 2008 nonfarm payroll employment data indicated a loss of 159,000 jobs. The second release (November 7, 2008) of the September 2008 employment data indicated a loss of 284,000 jobs. The third release (December 4, 2008) of the September 2008 data indicated a loss of 403,000 jobs. ALFRED, the FRED tool that captures data revisions, illustrates the change in data (see graph below).

\section{What's the Diff?}

For Major Economic Data, the first release is often based on incomplete data. For the Payroll Employment Data, on average, 73 percent of the data have been collected when the data are

*Actually, it is the third Friday after the conclusion of the reference week - that is, the week that includes the 12th of the month (https:// www.bls.gov/ces/ces_tabl.htm). first released. ${ }^{\dagger}$ Over time, more firms submit their data and the numbers become more accurate. The Payroll Employment Data are revised in the two following months after their release (so, a total of three releases initially). Then the data are again updated in a benchmark revision using the state unemployment data as the tool to benchmark the survey data. ${ }^{\ddagger}$ As a result of the revision process, these data can have significant changes within just a few short months. However, news reports generally focus on the latest number and not on the revisions to the previous months' data, and the more accurate information contained in those earlier months is generally not reported or discussed as much as the most recent (less accurate) data.

The Employment Data series is not the only one that is revised. GDP data are also revised many times as more data are collected. $₫$ The Bureau of Economic Analysis (BEA) estimates some of the elements of the Gross Domestic Product (GDP) statistics two times after the initial quarterly release, followed by an annual revision, then a comprehensive revision to GDP every five years. Some of the five year (benchmark) revisions can be substantial, reflecting changes in definitions and classifications.

As a general rule, economic data are revised and become more accurate over time. It is important to remember that nearly all Economic Data series are estimates-no one specifically asks every single person in the country if she or he is employed. Economic surveys are designed very carefully and the revisions are examined to determine if there are potential improvements in the estimations.

Why do data revisions matter? Decisions are often made using the most recent (and possibly incomplete) data. When people look back at decisions made, they often compare their decisions with the now more complete data and thus remove the decision from its context. As librarians, it is important to advise users of this feature of economic data.

$\dagger$ Nardone, Thomas; Robertson, Kenneth and Maxfield, Julie Hatch.

"Why Are There Revisions to the Jobs Numbers?" Beyond the Numbers: Employment \& Unemployment, vol. 2, no. 17. U.S. Bureau of Labor Statistics, July 2013; https://www.bls.gov/opub/btn/volume-2/revisions -to-jobs-numbers.htm.

‡ Information on the benchmarking is available at https://www.bls.gov /web/empsit/cesprelbmk.htm.

$\$$ For more information, see the BEA's discussion on their beablog, "Revising Economic Indicators: Here's Why the Numbers Can Change." July 8, 2013; https://blog.bea.gov/2013/07/08/revising-economic -indicators- $2 /$. 


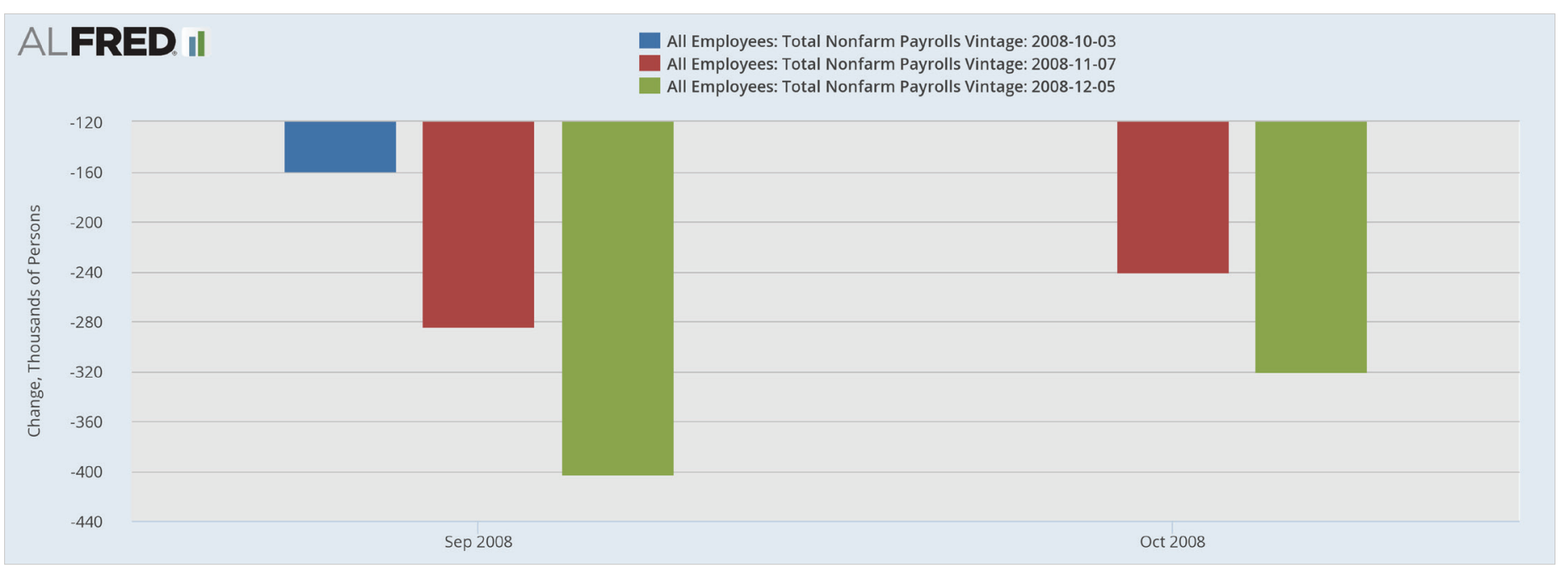

Source: U.S. Bureau of Labor Statistics, All Employees: Total Nonfarm Payrolls [PAYEMS], retrieved from ALFRED, Federal Reserve Bank of St. Louis; https:// alfred.stlouisfed.org/graph/?graph_id=354151, February 22, 2017.

\section{Finding Revisions}

So, how can you help your users find the revisions or the original data? There are several tools available, and they each have their users and fans.

\section{ALFRED (https://alfred.stlouisfed.org)}

The St. Louis Fed's FRED database has a parent: ALFRED. ALFRED captures all of the revisions of data added to FRED. In a few notable cases, staff have manually captured revisions to high-profile data series. ALFRED is a relatively simple tool to use-users can search for data in ALFRED and then select the vintage of data desired. So, if you would like the initial release of the December 1996 payroll employment data, you first find the data series (PAYEMS is the FRED mnemonic); then in the "edit graph" pane, select the vintage from January 1997 (because the initial release of the December data is the first Friday of the following month). Because so many data have different units, ALFRED works best when looking at a single series at a time.

\section{BEA Data Archive (https://www.bea.gov/histdata/)}

Data series published by the BEA have preserved the original vintage of the data. The releases generally go back to the early 2000s and are available by their release (National Accounts, Industry Accounts, International Accounts, Regional Accounts, and Integrated Macroeconomic Accounts).

\section{OECD Main Economic Indicators Original Release Data and Revisions Update:}

The Organisation for Economic Co-operation and Development (OECD) has captured the revisions to its Main Economic Indicators since 1999 (see http://stats.oecd.org/mei /default.asp?rev=1). The OECD revisions dataset provides online access to the original versions of the data published in the Main Economic Indicators database. The data come from all OECD member countries, the euro area, and non-OECD countries such as Brazil, China, India, South Africa, and the Russian Federation.

\section{Bank of England Real-Time Database (http://www .bankofengland.co.uk/statistics/pages/gdpdatabase /default.aspx)}

The Bank of England offers a handy set of Excel spreadsheets with vintage data for England back to January 1990. The data are updated every year and the vintage offered is as of the last working day of the month. Some quarterly data are available back to 1976.

\section{FRED-MD and FRED-QD (https://research.stlouisfed.org lecon/mccracken/fred-databases/)}

These data are specifically designed for users of macroeconomic data for forecasting and replication of empirical work. In short, they are most likely to be used by economists and economic forecasters.

9 McKenzie, Richard and Michela Gamba. "Data and Metadata Requirements for Building a Real-Time Database to Perform Revisions Analysis.” See http://www.oecd.org/std/40315408.pdf. 


\section{By the Numbers}

\section{Real-Time Data Research Center (https://www.phila} delphiafed.org/research-and-data/real-time-center /real-time-data)

The Philadelphia Fed has captured vintages of major macroeconomic time series. These data are available back to the mid1960s, by indicator, and available in Excel format.

\section{FRASER (https://fraser.stlouisfed.org)}

FRASER is a digital library of print economic publications, particularly collections of periodical data publications. FRASER provides digital copies of print publications, including the initial release of the data in the Press Release Employment
Situation, as well as more comprehensive publications such as Economic Indicators that can offer a broader snapshot of the economic picture at a moment in time. One downside of FRASER is that it is not available in a database format (e.g., Excel).

\section{A Final Note}

Regardless of which tool is used to capture data, it is important for users to remember the frequency of updates/revisions to the data. When citing a dataset, the version (e.g., initial, second, or third release) should be noted to avoid confusion and any perceived conflicts with data found in other datasets. 